\title{
A metastatic Marjolin's ulcer in a burn injury
}

\section{Samia Mrabat', Abdelhafid El Marfi², Sara Elloudi', Zakia Douhi', Hanane Baybay', Fatima Zahra Mernissi ${ }^{1}$, Abdelmajid EI Mrini ${ }^{2}$}

\author{
${ }^{1}$ Department of Dermatology, University Hospital Hassan II, Fes, Morocco, ${ }^{2}$ Department of Traumatology, University \\ Hospital Hassan II, Fes, Morocco
}

Corresponding author: Dr. Samia Mrabat, E-mail: samiamrabat91@gmail.com

Marjolin's ulcer is a tumour that most commonly arises from areas of chronic inflammation or injury and develop over many years [1]. The most common type of tumor in a Marjolin's ulcer is squamous cell carcinoma. However, other histological types have been described by Pavlovic et al such as as basal cell carcinoma and melanoma [2]. Marjolin's ulcers is more aggressive than primary cutaneous cancer with higher rates of local recurrence and metastasis [3]. We report the case of an agressive Marjolin's ulcer following a chronic burn injury.

A 38 years-old man, with a history of a burn injury 15 years ago, consulted for an ulcer in his thigh that has been growing for the last 15 years. Clinical examination found a well defined ulcerated tumor taking the entire anterior side of the left thigh (Fig. 1). Palpation of the groin revealed fixed ipsilateral inguinal lymphadenopathy. Skin biopsy showed moderately differentiated mature and invasive epidermoid carcinoma (Fig. 2). The computed tomography showed inguinal lymphadenopathies of tumoral appearance, as well as an invasion of the femoral bone. Given the aggressiveness of the tumor wich was invading the bone, the decision of the multidisciplinary consultation meeting was to perform an amputation. The patient refused to undergo the surgery and is now lost to follow-up.

\section{Consent}

The examination of the patient was conducted according to the Declaration of Helsinki principles.

The authors certify that they have obtained all appropriate patient consent forms. In the form the

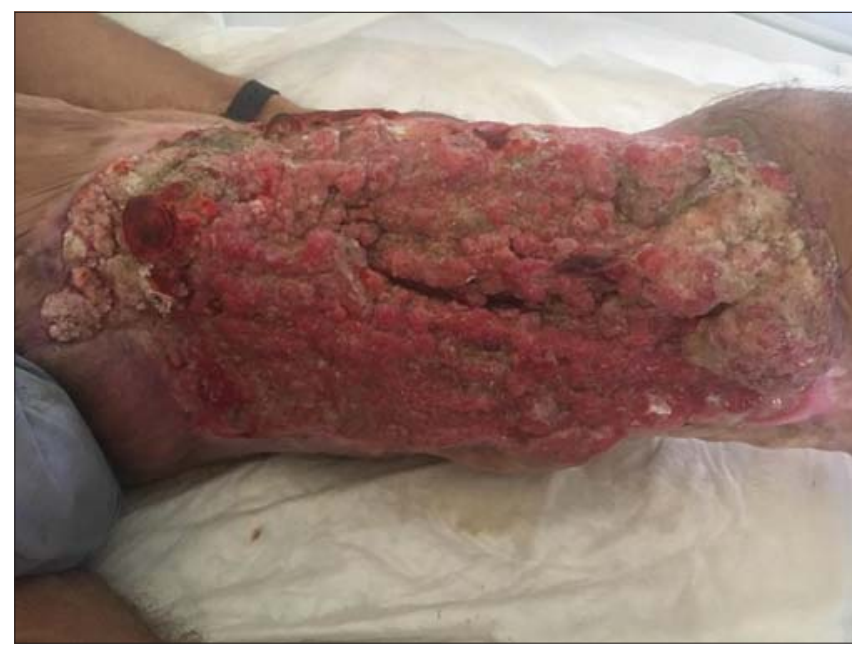

Figure 1: An ulcerated tumor of the left thigh arising in the site of a burn.

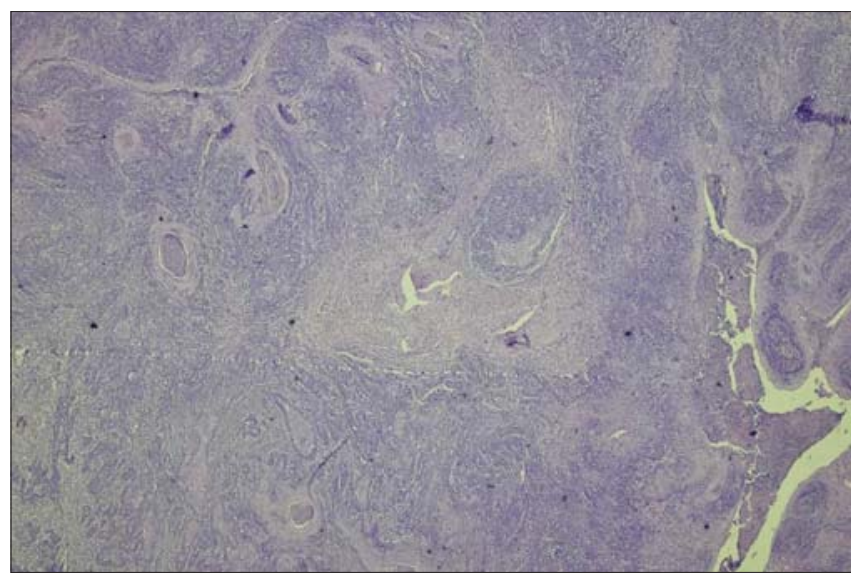

Figure 2: Carcinomatous tumoral proliferation, arranged in cords and sheets.

patient(s) has/have given his/her/their consent for his/ her/their images and other clinical information to be reported in the journal. The patients understand that their names and initials will not be published and

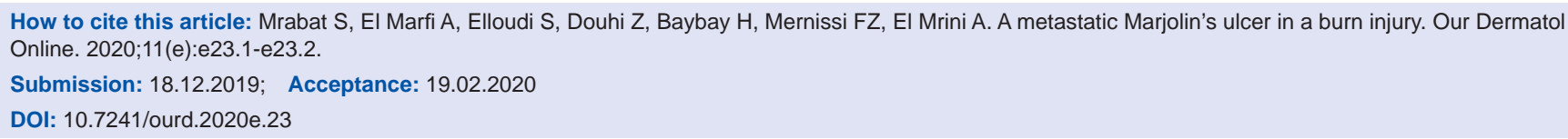


www.odermatol.com

due efforts will be made to conceal their identity, but anonymity cannot be guaranteed.

\section{REFERENCES}

1. Choa R, Rayatt S, Mahtani K. Marjolin's ulcer. BMJ. 2015;351:h3997.

2. Pavlovic S, Wiley E, Guzman G, Morris D, Braniecki M. Marjolin ulcer: an overlooked entity. Int Wound J. 2011;8:419-24.
3. Rowe DE, Carroll RJ, Day CL Jr. Prognostic factors for local recurrence, metastasis, and survival rates in squamous cell carcinoma of the skin, ear, and lip. Implications for treatment modality selection. J Am Acad Dermatol. 1992;26:976-90.

Copyright by Samia Mrabat, et al. This is an open access article distributed under the terms of the Creative Commons Attribution License, which permits unrestricted use, distribution, and reproduction in any medium, provided the original author and source are credited.

Source of Support: Nil, Conflict of Interest: None declared. 